\title{
Workload, occupational stress, and general health of female employees of public welfare centers
}

\author{
Beheshti MH, MSc ${ }^{1}$, Hajizadeh R, MSc ${ }^{2 *}$ \\ 1- Faculty Member, Dept. of Occupational Health, Faculty of Health, Gonabad University of Medical Sciences, Gonabad, \\ Iran. 2- PhD Student, Dept. of Occupational Health Engineering, School of Medical Sciences, Tarbiat Modares University, \\ Tehran, Iran.
}

\begin{abstract}
Received: April 2015, Accepted: May 2015

Background: The employees of welfare centers, due to the special conditions of their work, may be exposed to excessive occupational stress and workload. Thus, the aim of this study was to determine the effect of workload and occupational stress on the general health of female employees of public welfare centers.

Materials and Methods: This was a correlational research on 63 female employees of 3 welfare centers. The data were collected using the Occupational Stress Inventory (OSI), NASA Task Load Index (NASA-TLX), and General Health Questionnaire (GHQ). Data analysis was conducted using SPSS software by computing the Pearson and Spearman correlation coefficients and the stepwise regression.

Results: The general health score of $66 \%$ of staff of the welfare centers was higher than the cutoff point, as limit determinant of health and non-health. Among the different dimensions of general health, social disorders obtained the highest score; $74 \%$ of staff had social problems. The workload score of $12 \%$ of women was higher than 70 (high workload) and the workload score of $71.42 \%$ of women was between 40 and 70 (intermediate). Mean score of General Health Care of mentally ill disabled, and elderly employees was, respectively, 21.12, 27.21, and 24.90. The Occupational Stress Inventory score of the study population was 151.04, indicating that welfare employees were not exposed to high rates of stress in their work environment.

Conclusions: The results of the study suggest that authorities should pay special attention to ergonomics factors affecting the general health of welfare employees, especially with respect to social disorders. Moreover, personality traits should also be considered in employing of individuals.
\end{abstract}

Keywords: Workload, Mental Health, Stress, Employees

\section{Introduction}

Health is a multidimensional concept, which is why the definition of the World Health Organization (WHO) for health covers three physical, mental, and social dimensions $(1,2)$. Health promotion is a fundamental human need (1). The protection and promotion of health in occupational environments is a major task of managers and planners. In this regard, ergonomics is one of the most important sciences and can significantly help managers and planners to achieve health-related objectives. From an ergonomic point of view, the most critical factor involved in occupational accidents and injuries is the inconsistency between the workload, and abilities and limitations of people (3).

From a cognitive perspective, mental health is a variable of how people perceive and interpret the world, in particular, their surrounding environment (4). Studies have shown that physical and mental health can be affected by job-related factors (5). High workload, time restriction, and environmental stresses can severely affect the mental health of an individual (6). From an ergonomic perspective, there should be a balance between the workload and abilities of an individual, for

\footnotetext{
* Corresponding author: Roohollah Hajizadeh, Dept. of Occupational Health Engineering, School of Medical Sciences, Tarbiat Modares University, Tehran, Iran. Email: roohalahhajizade@gmail.com
} 
an imbalance in this regard can give rise to stressors (7).

Human health can be compromised as a result of stress, leading to an imbalance in physical and mental status. Long-term exposure to work-related stresses is one of the underlying causes of burnout (8). Stress is a physical, psychological, or social force that when applied to a system, can stimulate some significant changes. Lazarus and Folkman see stress as a special relationship between an individual and the environment, which is perceived as a sort of threat or demand which is beyond their ability and resources, and therefore, threatens their comfort and convenience (6). The role of stressful environments in creating the symptoms of depression is well-recognized; stressful life events can predict most depression symptoms (9). In today's world, one of the most crucial sources of stress is occupation (9). Occupational stress is a mental and emotional response motivated by imbalance between work demands and the abilities of an individual (10).

Occupational stress is an underlying factor in mental disorders, especially depression (11). The work life of each individual is characterized by various stressors that exert significant psychological pressure on their mind. Work-related developments such as organizational changes, salary change, promotions, layoffs and recruitments, and social transformation are among the factors that expose people to pressures of all kinds, casing anxiety, confusion, concern, and stress.

Occupational stress is of paramount importance in psychology; it was introduced as one of the malaises of the $20^{\text {th }}$ century by the United Nations in 1992, and later recognized as a rampant global issue by the WHO. The International Labor Organization (ILO) estimates that the costs incurred by occupational stress can account for 1 to $3.5 \%$ of the gross domestic product (GDP) of each country (12). The studies performed in Iran indicate that the prevalence of high occupational stress is about $14.4 \%(13,14)$.
The American Academy of Family Physicians (AAFP) has estimated that about two-thirds of those examined at their work environment or offices had symptoms of tension or stress (15). The literature on occupational stress reveal that $30 \%$ of the work force in developed countries suffer from job stress, whereas this figure is much greater in developing countries (16). The long-term exposure to stress can cause burnout (15). Occupational stress is characterized by the three groups of physical, psychological, and behavioral symptoms.

Previous studies suggest that high stress arising from work is associated with mild mental disorders. Problems such as excessive absenteeism, substance and drugs abuse, apathy at work, and low motivation are greater in stressed people, and these problems affect their job satisfaction and mental health. Job satisfaction is one of the most important factors contributing to improved performance, high efficiency, and reduced injuries (7). Stress is directly linked to the job satisfaction and performance of an individual, acting as one of the underlying components of health, safety, and comfort. Individuals with low job satisfaction display poor mental health (13). Unsatisfied employees are more vulnerable to physical and mental symptoms and absenteeism. The implementation of any plan to prevent and reduce job stress, promote job satisfaction, reduce workload, and increase general health requires deeper insights about these factors and their severity. Considering the paucity of research on the health conditions of welfare employees and their working conditions, this study seeks to investigate the relationship between general health, occupational stress, and workload.

\section{Materials and Methods}

This was a cross-sectional descriptivecorrelational study on 63 full-time employees of 3 welfare centers of Tehran, Iran, including the Care Center for the Mentally Ill, Care Center for the Disabled, and Care Center for the Elderly. Study subjects were selected using 
the the census method. The data collection tools consisted of the NASA Task Load Index (NASA-TLX) to evaluate workload, Occupational Stress Inventory (OSI) to evaluate occupational stress, and the General Health Questionnaire (GHQ-28) to examine the general health of the study population.

Moreover, another questionnaire was used to collect demographic data of the employees. Statistical data analysis was carried out using SPSS (version 17, SPSS Inc., Chicago, IL, USA) through computing the Spearman and Pearson correlation coefficients and step-wise regression. To observe the ethics of research, the necessary information about the goals of the study were given to the participants, they were assured of the confidentiality of study, and written consents were obtained from them before completing the OSI, NASA-TLX, and GHQ.

NASA-TLX: This questionnaire consists of two parts with the first part investigating overall workload and the second part determining the importance of each subscale of workload in the view of the respondent.

Part one: Evaluation of the relative importance of each subscale of workload

The subscales examined in this study include:

Mental demand: It refers to the extent of psychological activities (e.g. reflection, decision-making, calculation, remembering past events, and etc.), whether a task is simple, difficult, complex, or convenient.

Physical demand: It refers to the amount of physical activity required (e.g. pushing, pulling, physical movement, and etc.), whether the task is easy or demanding, requires quick reaction or is physically laborious.

Temporal demand: It refers to the pressure exerted as a result of time restriction of the task and whether it should be performed quickly or slowly.

Effort: It refers to the extent of hard work (in terms of intellectual and physical requirements) required to deliver the work at a desirable level.

Performance: It refers to the degree of achievement in the intended goals (occupational objectives) by an individual or their satisfaction with these goals.

Frustration: It refers to the level of frustration, dissatisfaction, annoyance, and stress a person is experiencing (it is the opposite of hopefulness, peace, and satisfaction).

Part two: Determining the level of each subscale of workload (in a scale of 0-100)

The respondent's/participant's scores in each subscale of workload, in accordance with their personal condition, ranged from 0 to 100 .

In the analytic hierarchy process (AHP), the importance of each dimension is compared to other dimensions (this one-to-one analysis was part of the questionnaire where the respondents were required to answer the questions based on their conditions and criteria specified in the definition of each in the first part of the questionnaire. The analysis was performed on the basis of choices made by the respondents. In other words, the parameters were presented in the questionnaire and choices/comparisons were made by the respondents. The weight of each dimension was obtained from the total workload of each respondent. Then, multiplying the weight of each workload subscale (a value between 0 and 1) by the specified level (a number between 0 and 100), the total workload of each individual was calculated as a number between 0 and 100 .

GHQ-28 This psychological questionnaire is the most well-known screening tool in psychiatry. It was designed by Goldberg and Hillier (17). This 28-item questionnaire consists of 4 scales each containing 7 items that evaluate physical symptoms, anxiety, impaired social functioning, and depression. The intensity of these scales is evaluated on a range of extremely low to extremely high with each item having a score of 0-3. In this study, which was carried out in Iran, a cutoff score of 21 was obtained (18).

Osipow job stress questionnaire: This questionnaire, which was designed by Osipow and Spokane in 1987, is an occupational stress measurement instrument (19). In Iran this questionnaire has been used in several studies 
and its validity and reliability (with a Cronbach's alpha of 0.89 ) has been confirmed. $(13,31,32)$, in the study by Namavar et al. in 2013, a reliability of 0.87 was achieved using Cronbach's alpha (20).

The OSI is scored based on a 5-point Likert scale and consists of three parts. In this study, only the first part of the questionnaire has been used. This part is organized in 6 subscales, each containing 10 items. The first subscale is role workload, which evaluates the reaction of a person to their work environment. The second subscale is role insufficiency, which determines the consistency between skills, knowledge, and educational and empirical features relative to the job environment requirements. The third subscale is role duality, which is concerned with the knowledge of priorities and expectations of the work environment and evaluation criteria. The fourth subscale is role boundary, which is related to the contradictions among work ethic and the requirements of the expected role. The fifth subscale is responsibility, which determines the sense of accountability in terms of efficiency and welfare of others. The sixth subscale is physical environment, which is related to exposure to unsuitable physical environment. In this scale, occupational stress is evaluated at four levels of low, normal, moderate, and severe stress.

In this research, the necessary permissions were obtained from the Research Deputy of Gonabad University of Medical Sciences, Iran, and presented to the Welfare Center of Tehran. Then, the questionnaires were distributed among the employees, with the assurance that their participation was voluntary and their information would remain confidential and anonymous.

Table 1: Description of each subscale of workload in welfare employees

\begin{tabular}{cccccccc}
\hline & $\begin{array}{c}\text { Mental } \\
\text { demand }\end{array}$ & $\begin{array}{c}\text { Physical } \\
\text { demand }\end{array}$ & $\begin{array}{c}\text { Temporal } \\
\text { demand }\end{array}$ & Effort & Performance & Frustration & $\begin{array}{c}\text { Total } \\
\text { workload }\end{array}$ \\
\hline Mean & 70.27 & 62.8 & 54.98 & 67.03 & 40.86 & 39.38 & 55.76 \\
\hline SD & 26.48 & 27.04 & 26.86 & 25.09 & 30.69 & 31.88 & 16.91 \\
\hline Min & 2 & 8 & 0 & 3 & 0 & 0 & 20.67 \\
\hline Max & 100 & 100 & 100 & 100 & 100 & 100 & 100 \\
\hline
\end{tabular}

\section{Results}

In this paper, 63 female employees of welfare centers, with an average age of 39 years and, respectively, minimum and maximum age of 23 and 65 years, were studied. The average work experience of employees was 6.92 years with a maximum and minimum of 1 to 21 years, respectively. Amongst the participants, 16 were single and 47 were married. A description of workload data of the study population is shown in table 1 and figure 1 .
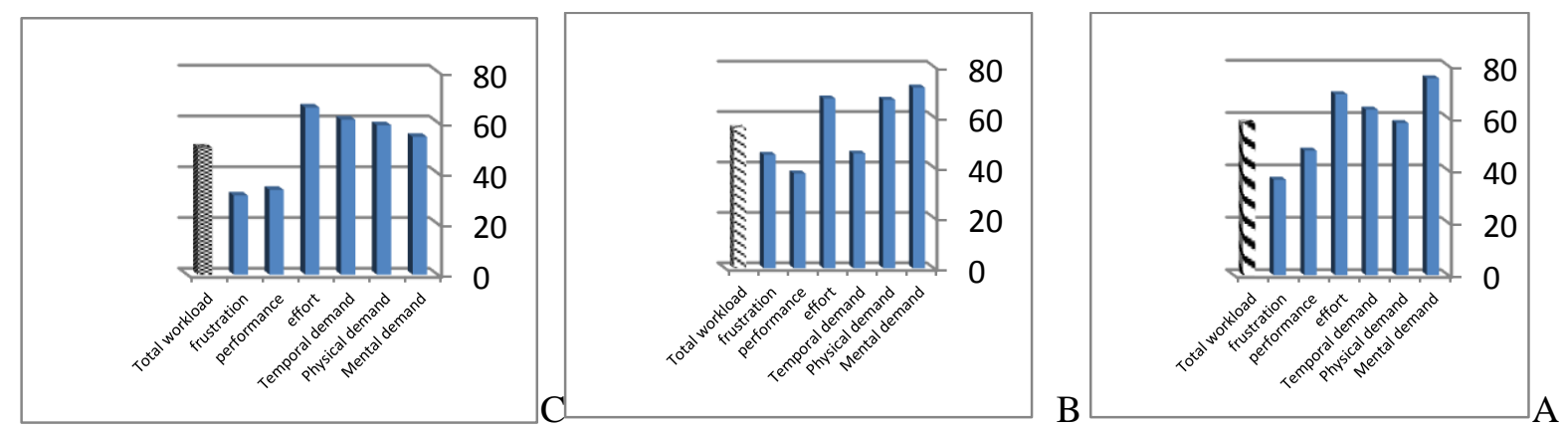

Figure 1: Workload in the Care Center for the Mentally Ill (A), Care Center for the Disabled (B) and Care Center for the Elderly $(C)$ 
The results of the analysis of workload variables using the NASA-TLX indicated that the two aspects of mental demand and effort, with a score of 70.27 and 67.03, respectively, had the highest scores. Moreover, frustration and performance, with a score of 39.38 and
40.86, respectively, had the lowest scores among the subscales of the NASA-TLX. The results of measuring different subscales of occupational stress in welfare employees are presented in table 2 .

Table 2: Results of measuring job stress in welfare employees

\begin{tabular}{lcccccccc}
$\begin{array}{l}\text { Welfare } \\
\text { Center }\end{array}$ & & $\begin{array}{c}\text { Job } \\
\text { stress }\end{array}$ & $\begin{array}{c}\text { Physical } \\
\text { environment }\end{array}$ & Responsibility & $\begin{array}{c}\text { Role } \\
\text { boundary }\end{array}$ & $\begin{array}{c}\text { Role } \\
\text { duality }\end{array}$ & $\begin{array}{c}\text { Role } \\
\text { insufficiency }\end{array}$ & $\begin{array}{c}\text { Role } \\
\text { workload }\end{array}$ \\
\hline Care & Mean & 146.60 & 19.64 & 26.40 & 25.44 & 23.28 & 27.04 & 24.8 \\
Center & SD & 17.176 & 4.881 & 4.262 & 4.194 & 6.554 & 5.891 & 4.5 \\
for the & Min & 118 & 13 & 16 & 19 & 10 & 14 & 19 \\
Mentally & Max & 182 & 30 & 35 & 37 & 37 & 38 & 34 \\
Ill & Mean & 158.29 & 25.14 & 27.32 & 26.89 & 23.86 & 29.82 & 25.25 \\
Care & SD & 26.425 & 6.508 & 6.337 & 5.202 & 8.077 & 9.858 & 6.479 \\
Center & Min & 118 & 15 & 18 & 18 & 10 & 12 & 12 \\
for the & Max & 206 & 38 & 39 & 37 & 37 & 47 & 36 \\
Disabled & Mean & 146.50 & 21.20 & 34.00 & 20.20 & 20.50 & 24.70 & 25.90 \\
\hline Care & SD & 25.127 & 8.548 & 3.333 & 5.574 & 5.061 & 6.038 & 7.355 \\
Center & Min & 114 & 15 & 27 & 12 & 15 & 17 & 16 \\
for the & Max & 195 & 45 & 37 & 28 & 28 & 35 & 33 \\
\hline
\end{tabular}

According to the results, the mean score of occupational stress in the study population was $151.04 \pm 23.33$. The results of table 2 indicate that responsibility, with a mean score of 28.02 \pm 5.76 , has a greater impact on increasing job stress compared to other variables.
Furthermore, physical environment, with a mean score of $2 \pm 22.33$, has the lowest effect on increasing job stress. The results of the general health examination of employees are illustrated in table 3 .

Table 3: Results of the general health of welfare employees

\begin{tabular}{|c|c|c|c|c|c|c|}
\hline Welfare center & & $\begin{array}{c}\text { General } \\
\text { health }\end{array}$ & Depression & $\begin{array}{c}\text { Social } \\
\text { disorders }\end{array}$ & $\begin{array}{c}\text { Anxiety and sleep } \\
\text { disorders }\end{array}$ & $\begin{array}{c}\text { Physical } \\
\text { symptoms } \\
\end{array}$ \\
\hline \multirow{4}{*}{$\begin{array}{l}\text { Care Center for } \\
\text { the Mentally Ill }\end{array}$} & Mean & 21.12 & 1.72 & 8.44 & 5.24 & 5.72 \\
\hline & $\mathrm{SD}$ & 9.01 & 2.82 & 2.74 & 4.82 & 3.53 \\
\hline & Min & 11 & 0 & 4 & 0 & 1 \\
\hline & Max & 39 & 9 & 15 & 14 & 15 \\
\hline \multirow{4}{*}{$\begin{array}{l}\text { Care Center for } \\
\text { the Disabled }\end{array}$} & Mean & 27.21 & 4.57 & 9.07 & 7.04 & 6.61 \\
\hline & $\mathrm{SD}$ & 9.79 & 4.63 & 4.56 & 3.69 & 3.56 \\
\hline & Min & 7 & 0 & 2 & 0 & 1 \\
\hline & Max & 42 & 14 & 18 & 14 & 13 \\
\hline \multirow{4}{*}{$\begin{array}{l}\text { Care Center for } \\
\text { the Elderly }\end{array}$} & Mean & 24.9 & 2.6 & 14.60 & 3.8 & 3.09 \\
\hline & $\mathrm{SD}$ & 6.20 & 3.92 & 5.52 & 4.96 & 2.42 \\
\hline & Min & 16 & 0 & 6 & 0 & 2 \\
\hline & $\operatorname{Max}$ & 39 & 11 & 19 & 14 & 10 \\
\hline
\end{tabular}

According to the results of this study, social disorders and physical symptoms obtained the highest and lowest scores in general health, respectively. The results of workload regression on job stress were shown to be significant $(P=0.012)$. However, the model has a weak predictable power, with the regression model accounting for only about 
$10 \%$ change in the variables $\left(\mathrm{R}^{2}=0.098\right)$. Accordingly, the regression model related tojob stress and workload is as follows:

Job stress $=0.432 *$ workload +127.67

The statistical data analysis also showed that job stress regression on general health was significant $(P=0.001)$, despite the weak predictive power of the model in which the regression model accounted for only about $16 \%$ of the variable changes $\left(R^{2}=0.161\right)$. According to the results, the regression model will be as follows:

General health $=0.149+$ job stress $* 0.160$

The results also suggested that the workload regression on job stress was significant $(\mathrm{P}=$ 0.066), whereas the effect of independent workload variables on general health was not significant $(\mathrm{P}=0.060)$. The results of statistical analysis for determining the effect of each subscale of workload on general health are shown in table 4.

Table 4: Pearson correlation coefficient between workloadsubscales and general health

\begin{tabular}{lcccccccc}
\hline $\begin{array}{l}\text { General } \\
\text { health }\end{array}$ & Frustration & Performance & Effort & $\begin{array}{c}\text { Temporal } \\
\text { demand }\end{array}$ & $\begin{array}{c}\text { Physical } \\
\text { demand }\end{array}$ & $\begin{array}{c}\text { Mental } \\
\text { demand }\end{array}$ \\
\cline { 2 - 8 } & $\begin{array}{c}\text { Correlation } \\
\text { coefficient }\end{array}$ & 0.30 & 0.10 & 0.10 & $* 0.20$ & 0.18 & 0.09 \\
\cline { 2 - 9 } & $\mathbf{P}$ & 0.01 & 0.39 & 0.40 & 0.84 & 0.15 & 0.47 \\
\hline
\end{tabular}

* Pearson correlation coefficient

According to the above table, there is only a significant relationship between frustration and general health $(\mathrm{P}=0.015)$. The results of statistical analysis showed that frustration regression on general health was significant $(\mathrm{P}$ $=0.003)$, although the model had a weak predictive power and the model regression explained only $13 \%$ of the changes in variable $\left(\mathrm{R}^{2}=0.132\right)$. The relevant regression model is as follows:

General health $=20.24+$ frustration $* 0.106$ The results of the statistical analysis of the effect of each job stress subscale on general health are presented in table 5 .

Table 5: Pearson correlation coefficient between the subscales of job stress and general health

\begin{tabular}{|c|c|c|c|c|c|c|c|}
\hline \multirow[t]{3}{*}{$\begin{array}{l}\text { General } \\
\text { health }\end{array}$} & & Environment & Responsibility & $\begin{array}{c}\text { Role } \\
\text { duality }\end{array}$ & $\begin{array}{c}\text { Role } \\
\text { insufficiency }\end{array}$ & $\begin{array}{c}\text { Role } \\
\text { workload }\end{array}$ & \\
\hline & $\begin{array}{c}\text { Correlation } \\
\text { coefficient }\end{array}$ & $* 0.51$ & 0.27 & 0.08 & $* 0.27$ & 0.17 & 0.18 \\
\hline & $\mathbf{P}$ & $<0.001$ & 0.03 & 0.48 & 0.10 & 0.17 & 0.15 \\
\hline
\end{tabular}

To determine the role of the occupational stress subscales on general health, first the relationship between each subscale and general health was investigated. The results of table 5 show that responsibility and physical environment are significantly related to general health $(\mathrm{P}<0.050)$.

The results of statistical analysis suggest that the regression of physical environment and responsibility on general health is significant. However, the model has a weak predictive power with the regression model explaining only $29 \%$ of the changes in variables $\left(\mathrm{R}^{2}=\right.$
0.292). The regression model is as follows:

General health $=0.382 *$ responsibility + $0.681 *$ physical environment

\section{Discussion}

According to the results, considering the cutoff point of 21 as the separating line between health and non-health in the study population, the general health score of welfare employees was too high (24.43), suggesting the undesirability of their health conditions. Amongst the different subscales of general health, social disorders had the highest score. 
The social aspect of health can be seen as the most complex and yet controversial aspect of the health system.

The WHO introduces social health as one of the key components of health, but due to lack of valid instrument, this concept is still the subject of political and social debates (6). Several studies have substantiated the effect of the work environment and work requirements on general health. There is a paucity of studies on occupational health of welfare employees. The study by Movallali et al. on the quality of general health in mothers of hearing and hearing-impaired children indicated that the general health of mothers of hearing children was greater than that of mothers of hearingimpaired children (21).

The results of the study revealed that workload, with a mean score of 55.76, was at the medium level. The two subscales of mental demand and effort had the highest and frustration and performance subscales the lowest scores among the subscales of NASATLX. This, in turn, suggests the high mental demand and physical requirements of work in welfare centers. There are few studies on the evaluation of workload in welfare employees using the NASA-TLX.

The level of job stress in the study population was normal according to the rating scale of 60 to 107 (without stress), 108-203 (normal), 204251 (medium), and 252-300 (severe). This indicated that welfare employees were not exposed to high levels of stress in their work environment. The analysis of job stress subscales showed that role workload, role insufficiency, responsibility, and physical environment were at the normal range, and role duality and role boundary were at the medium range.

The study suggested that the effect of responsibility on increasing job stress was greater than other variables. The results of workload regression on job stress were shown to be significant. Moreover, statistical data indicated that the regression of job stress and frustration on general health was significant. In determining the role of each dimension, only the significant relationship between responsibility and physical environment, and general health was corroborated.

The study by Yadegarfar et al. revealed that high stress increased the risk of some cardiovascular risk factors (14). The study by Navidian et al. showed a significant relationship between the intensity of stress factors and general health of nurses. That is, an increase in intensity of stress factors was associated with deteriorated general health (negative correlation coefficient) (6). Most relevant studies in this field confirm the relationship between the intensity of job stress experienced by individuals and their mental health status $(6,22,23)$.

The relationship between occupational stress and many cardiovascular risk factors, including diabetes (24), body mass index (25), hypertension, hyperlipidemia, overweight, smoking, alcohol consumption and its severity, triglyceride and lipoproteins levels with high and low density (26-28), heart rhythm, and metabolic syndrome (28), have been investigated. However, the findings in this field are incongruous $(26,29,30)$. There have been numerous studies on job stress in Western countries. But due to the different in job values and perceived characteristics of work environment, motivation and attitude in Iran and other country there is a high chance of obtaining different results in Iran. Of course, this inconsistency is not far from expectation since stress and workload, as psychological phenomena, are affected by a range of factors, including job-induced stress and workload. There are many risk factors that can intensify job stress and workload. Nevertheless, it should be noted that stress and workload are to a large extent generated by risk factors stimulated by individuals. In addition to environmental factors and stressors, intrapersonal factors such as cognitive, attitudinal, emotional, and personal components are also involved in increasing stress and workload.

According to the results of other studies, measures, such as recruiting more employees, 
and therefore, reducing the workload, utilizing the services of people interested and experienced in these fields, providing a comfortable and appropriate physical environment, dedicating a break time for relaxation after critical situations, and alleviating the workload, can help reduce the above stressors (6). By identifying stressors in these jobs and attempting to reduce them through reforms in organizational, physical, and caring structures, we can reduce stress and promote the physical and psychological health and job satisfaction of employees. This will result in the increasing of the quality of life of people engaged in these jobs. It is recommended that at the outset of recruiting, some psychological tests, such as personality characteristics, be administered to the applicants and regular examinations be offered to them at centers specialized in occupational medicine services. Moreover, regular training programs and medical and psychological education should be provided for these individuals.

\section{Conclusions}

Given the results of the present study and with a view of the body of research on personality characteristics and job stress, in can be concluded that there is a significant relationship between some basic subscales of workload, job stress, and general health.

The present study had a number of limitations. The research data are based on selfmonitoring, which may be biased. Moreover, this research is limited to social welfare employees in the city of Tehran. Thus, caution should be practiced in generalizing its results to other groups. In addition, since it is a correlational study, it is difficult to discover causal relationship. Thus, to identify the causes of job stress, workload, and general health, experimental research or causal studies are required.

\section{Acknowledgement}

The authors are grateful to faculty members of the Department of Occupational Health in Tehran University of Medical Sciences, and all managers and staff of welfare centers in Tehran who helped us in this project.

Conflict of interests: None declared.

\section{References}

1. Samiee M, Rafiee H, Amini-Rarani M, Akbarian M. Social health of Iran: from a consensus-based definition to an evidence-based index. Quarterly social problems of Iran 2011; 1(2):31-51.

2. Kivimaki M, Leino-Arjas $\mathrm{P}$, Luukkonen $\mathrm{R}$, Riihimäi H, Vahtera J, Kirjonen J. Work stress and risk of cardiovascular mortality: prospective cohort study of industrial employees. BMJ 2002; 325(7369):857.

3. Paterson JL, Dorrian J, Pincombe J, Grech C, Dawson D. Mood change and perception of workload in Australian midwives. Ind Health 2010; 48(4):381-9

4. Younesi SJ, Bahrami F. Prediction of marital satisfaction and deterministic thinking in couples. Journal of Iranian Psychologists. 2009;5(19):241-50.

5. Behrouzian F, Khajeddin N, Hodaei F, Zamani $\mathrm{N}$. The relationship of job satisfaction and coping mechanism with general health, among private industrial's staff. Jundishapur Scientific Medical Journal 2009; 8(3):345-53.

6. Navidian A, Masoudi GR, Mousavi SS. Workrelated stress and the general health of nursing staffs in Zahedans' Hospitals emergency wards (2003). Journal of Kermanshah University of Medical Sciences 2005; 9(3):17-26.

7. Khandan M, Roshanzamir S, Maghsoudipour M. Survey of Workload and Job Satisfaction relationship in a Productive Company. Iran Occupational Health 2012; 9(1):30-6.

8. Abdi H, shahbazi L. Job stress among nurses working in intensive care unit and its relationship with job burnout. The Journal of Shahid Sadughi University of Medical Sciences 2001; 9(3):64-70.

9. Eremsoy CE, Celimli S, Gencoz T. Students under academic stress in a Turkish University: Variables associated with symptoms of depression and anxiety. Curr Psychol 2005; 24(2):123-33.

10. Peter R, Siegrist J. Psychosocial work environment and the risk of coronary heart disease. Int Arch Occup Environ Health 2000; 73Suppl:S41-5.

11. Kawakami N, Haratani T. Epidemiology of job stress and health in Japan: review of current 
evidence and future direction. Ind Health 1999; 37(2):174-86.

12. Tangri R. Stress costs, Stress-cures. Britain: Trafford Publishing; 2003.

13. Abdi H, Kalani Z, Harazi MA. Job stress in nurses. The Journal of Shahid Sadughi University of Medical Sciences 2001; 8(4):17-21.

14. Yadegarfar G, Alinia T, Gharaaghaji R, Allahyari T, Sheikhbagloo R. Study of Association between Job Stress and Cardiovascular Disease Risk Factors among Urmia Petrochemical Company Personell. Journal of Isfahan Medical School 2010; 28(112):645-60.

15. Embriaco N, Papazian L, Kentish-Barnes N, Pochard F, Azoulay E. Burnout syndrome among critical care healthcare workers. Curr Opin Crit Care 2007; 13(5):482-8.

16. Mathee A, Oba J, Rose A. Climate change impacts on working people (the HOTHAPS initiative): findings of the South African pilot study. Global Health Action 2010; 3:5612. Doi:10.3402/gha.v3i0.5612

17. Goldberg DP, Hillier VF. A scaled version of the General Health Questionnaire. Psychol Med 1979; 9(1):139-45.

18. Yaghoubi N, Nasr M, Shah-Mohammadi D. Prevalence of mental disorders in Someesara (Gilan) rural and urban areas. [Phd Thesis]. Tehran: Iran University of Medical Sciences; 1995.

19. Osipow SH, Spokane AR. Occupational stress inventory-revised. Odessa, FL: Psychological 1998:1-15.

20. Namavar S, Rahmani Gh, Rezanejad MT, Gholami L. Evaluation of job stress on the staff of the National Gas Company and distribution of petroleum products in Yasuj in 2013. Paper presented at: $16^{\text {th }}$ the national Conference on Environmental Health; 2013 Oct 1-3 Tabriz, Iran.

21. Movallali G, Rafi MA, Nemati S. Comparison of general health status in mothers of hearing and hearing-impaired children. Audiol 2013; 22(2):33-9.

22. Laposa JM, Alden LE, Fullerton LM. Work stress and posttraumatic stress disorder in ED nurses/personnel. J Emerg Nurs 2003; 29(1):238 .
23. Spector PE, Zhou ZE, Che XX. Nurse exposure to physical and nonphysical violence, bullying, and sexual harassment: a quantitative review. Int J Nurs Stud 2014; 51(1):72-84.

24. Agardh EE, Ahlbom A, Andersson T, Efendic S, Grill V, Hallqvist J, et al. Work stress and low sense of coherence is associated with type 2 diabetes in middle-aged Swedish women. Diabetes Care 2003; 26(3):719-24.

25. Kouvonen A, Kivimäki M, Cox SJ, Cox T, Vahtera J. Relationship between work stress and body mass index among 45,810 female and male employees. Psychosom Med 2005; 67(4):577-83.

26. Niedhammer I, Goldberg M, Leclerc A, David S, Bugel I, Landre MF. Psychosocial work environment and cardiovascular risk factors in an occupational cohort in France. J Epidemiol Community Health 1998; 52(2):93-100.

27. Kouvonen A, Kivimäki M, Virtanen M, Pentti J, Vahtera J. Work stress, smoking status, and smoking intensity: an observational study of 46 190 employees. J Epidemiol Community Health 2005; 59(1):63-9.

28. Kang MG, Koh SB, Cha BS, Park JK, Woo JM, Chang SJ. Association between job stress on heart rate variability and metabolic syndrome in shipyard male workers. Yonsei Med J 2004; 45(5):838-46.

29. Bosma H, Peter R, Siegrist J, Marmot M. Two alternative job stress models and the risk of coronary heart disease. Am J Public Health 1998; 88(1):68-74.

30. Peter R, Alfredsson L, Hammar N, Siegrist J, Theorell T, Westerholm P. High effort, low reward, and cardiovascular risk factors in employed Swedish men and women: baseline results from the WOLF Study. J Epidemiol Community Health 1998; 52(9):540-7.

31. Aghilinejad M, Mohammadi S, Afkari M, Abbaszade Dizaji R. Surveying the association between occupational stress and mental health, personality and life stressful events in Tehran police officers. Pejouhesh 2007; 31(4):355-60.

32. Ghasemi Nejad A, Siadat A. The relationship between organizational climate with job stress and its effects on secondary teachers. Daneshvar Raftar 2004; 11(8):55-64. 